\title{
Autosomal recessive limb-girdle muscular dystrophy type 2L
}

INSERM

\section{Source}

INSERM. (1999). Orphanet: an online rare disease and orphan drug data base. Autosomal recessive limb-girdle muscular dystrophy type 2L. ORPHA:206549

Autosomal recessive limb-girdle muscular dystrophy type 2 L (LGMD2L) is a form of limbgirdle muscular dystrophy most often characterized by an adult onset (but rang ing from 11 to 51 years) of mainly proximal lower limb weakness, with difficulties standing on tiptoes being one of the initial signs. Proximal upper limb and distal lower limb weakness is also common, as well as atrophy of the quadriceps (most commonly), biceps brachii, and lower leg muscles. Calf hypertrophy has also been reported in some cases. LGMD2L progresses slowly, with most patients remaining ambulatory until late adulthood. 